\title{
Pneumoencephalo-roulette tomography of operated primary pontine haemorrhage with long survival: report of two cases
}

\author{
M. KOWADA, K. YAMAGUCHI, Z. ITO, AND S. MATSUOKA \\ From the Division of Surgical Neurology and Radiology, \\ Research Institute of Brain and Blood Vessels, Akita, Japan
}

SUMMARY Pre- and postoperative pneumoencephalo-roulette tomography has been carried out in two cases of primary pontine haemorrhage with long survival. A pontine or cerebellar atrophy was revealed in case 1 , in whom an intrapontine haematoma was removed. A markedly hollowed pons on the affected side has been demonstrated nearly five months after ventriculoatrial shunting in case 2.

\begin{abstract}
'Pneumoencephalo-roulette tomography' (Matsukawa, Iwai, and Fukatsu, 1962; Iwabuchi and Suzuki, 1968) has recently been carried out in seven cases of primary pontine haemorrhage in our clinic. Roulette tomograms have made it possible to demonstrate clearly an expansive mass lesion in the brain-stem during life. Evacuation of the haematoma and ventriculoatrial shunting was performed in two of these cases. The surgically treated patients have had long survivals and changes in shape of the brain-stem have been observed by pre- and postoperative pneumoencephalo-roulette tomography.
\end{abstract}

\section{CASE 1}

A 47 year old male entered the hospital shortly after sudden onset of vomiting and loss of consciousness on 13 May 1969. On admission the patient was in a comatose state. Examination revealed tetraplegia, lateral gaze paralysis, miotic pupils, bilateral Babinski sign, and systemic blood pressure of $160 / 90 \mathrm{~mm} \mathrm{Hg}$. Lumbar puncture showed grossly bloody cerebrospinal fluid with an initial pressure of $110 \mathrm{~mm} \mathrm{H}_{2} \mathrm{O}$. Bilateral carotid and vertebral angiograms revealed no vascular abnormalities. Clinical diagnosis was pontine haemorrhage and the patient remained in coma. Pneumoencephalo-roulette tomography carried out on the 33rd hospital day demonstrated a mass lesion protruding into the fourth ventricle, suggesting a haematoma localized relatively in the right dorsal portion of the pons (Fig. 1).

A haematoma of approximately $10 \times 6 \mathrm{~mm}$ was evacuated through a suboccipital craniectomy on the 39th hospital day. Histological examination showed no evidence of neoplasm or haemangioma in any of the evacuated materials. The patient became able to recognize his family two months after operation. Postoperative pneumoencephalo-roulette tomography performed on 11 November 1969 showed no mass lesion and the pons itself seemed to have decreased in size in comparison with the preoperative tomogram (Fig. 2). A third tomogram performed on 27 October 1970 demonstrated an enlarged fourth ventricle and aqueduct of Sylvius, suggesting cerebellar and pontine atrophy (Fig. 3). The patient was discharged from the hospital on 7 November 1970 with paresis of the right III, VII, VIII, and IX cranial nerves and bilateral paresis of the extremities.

\section{CASE 2}

A 41 year old male entered the hospital shortly after sudden loss of consciousness on 19 October 1970. He was comatose on admission and the systemic blood pressure was $150 / 90 \mathrm{~mm} \mathrm{Hg}$. Examination showed skew deviation of the eyeballs, pinpoint pupils, tetraplegia with increased deep tendon reflexes, and a Babinski sign on the left side. Lumbar puncture revealed haemorrhagic cerebrospinal fluid with an initial pressure of $220 \mathrm{~mm} \mathrm{H}_{2} \mathrm{O}$. Bilateral serial carotid angiograms did not show any vascular abnormalities. Vertebral serial angiography revealed anterior displacement of the basilar artery. Combined pneumoencephalo-pneumoventriculography demonstrated an expansive mass lesion in the upper portion of the pons and an occlusion of the aqueduct of Sylvius (Fig. 4).

The patient regained consciousness 20 days after ventriculoatrial shunting, and was so much improved that it was possible for him to be shown 


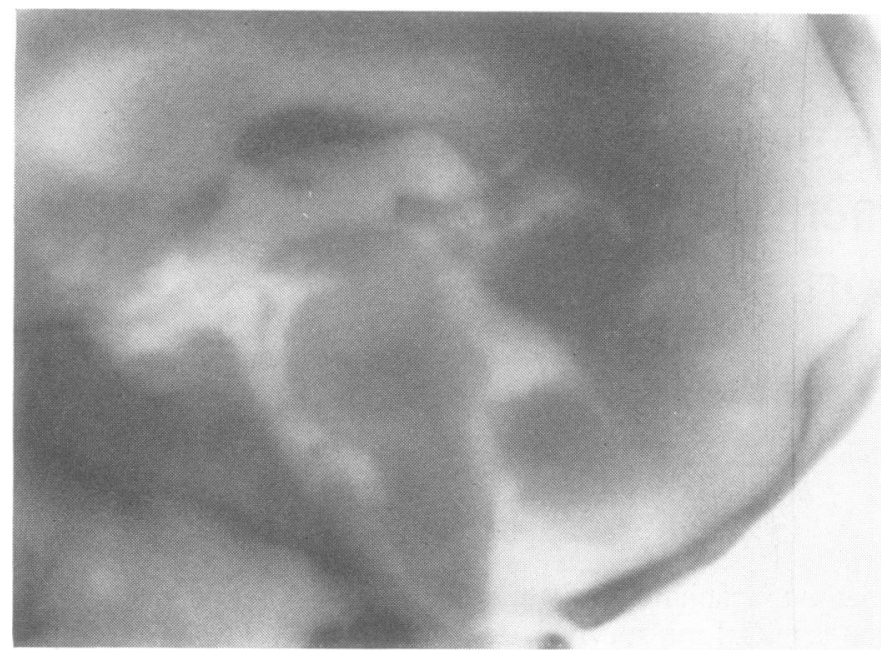

FIG. 1. Case 1. Preoperative pneumoencephalo-roulette tomogram. $A$ haematoma is demonstrated in the dorsal portion of the pons.

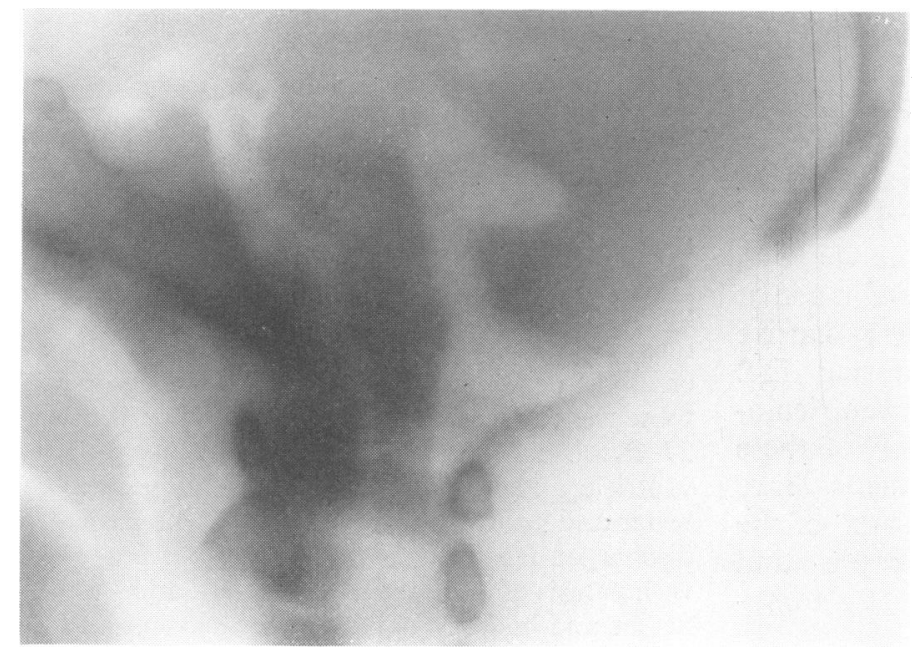

FIG. 2. Case 1. Postoperative tomogram.

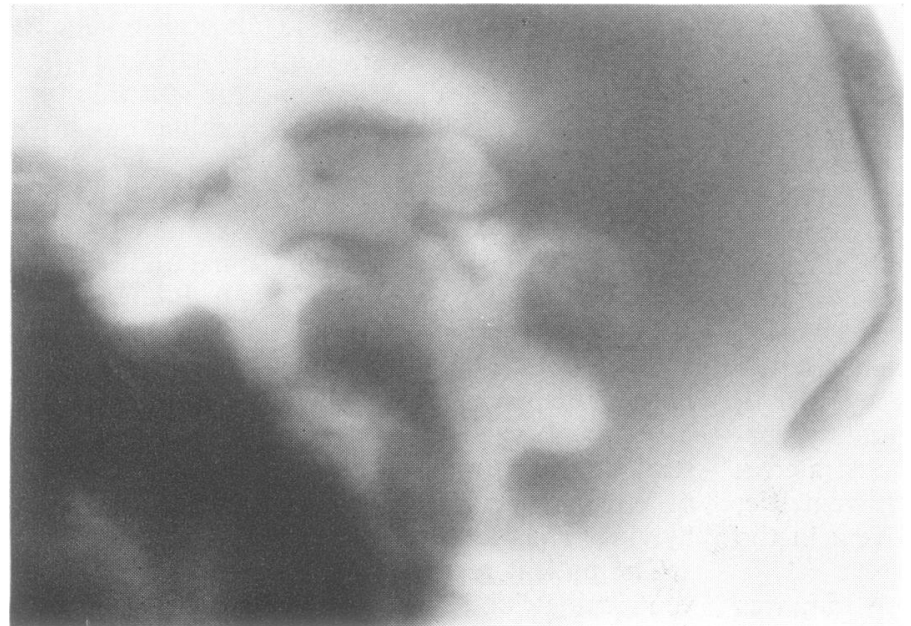

FIG. 3. Case 1. The third tomogram. 


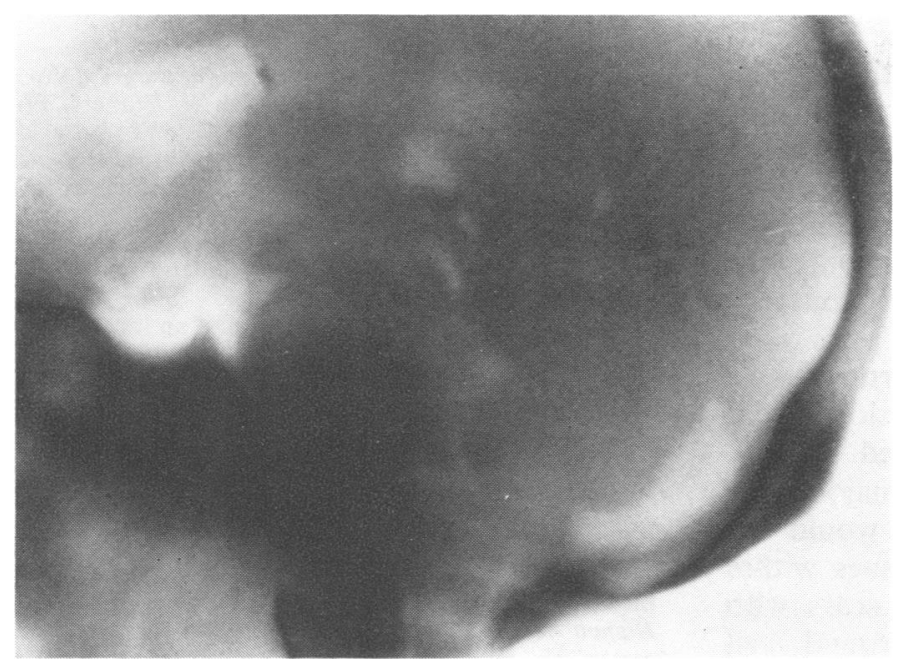

FIG. 4. Case 2. Preoperative pneumoencephalo-roulette tomogram. An expansive mass lesion is revealed in the pons.

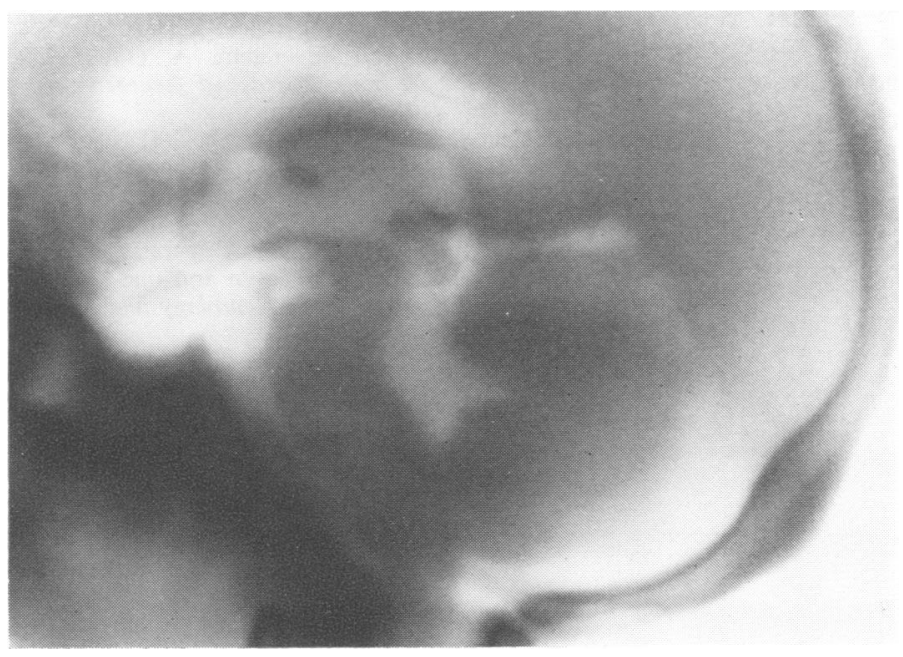

FIG. 5. Case 2. Postoperative tomogram.

around with a hand-cart. Reopening of the aqueduct of Sylvius was verified by postoperative pneumoencephalo-roulette tomography on 4 March 1971. The dorsal portion of the pons was markedly hollowed and the extensive mass lesion had disappeared (Fig. 5). He was discharged from the hospital for physical therapy on 17 April 1971.

\section{DISCUSSION}

Combined pneumoencephalo-pneumoventriculoroulette tomography has been recently developed in our clinic. Pneumoencephalography is usually contraindicated in mass lesions in the posterior fossa. Pneumoventriculography is performed first and then contrast air is injected carefully by lumbar puncture, controlling the difference between supra- and infratentorial pressure through the ventricular drainage. Space occupying lesions, the shape of the brain-stem or the cerebellum, and stenosis or occlusion of the aqueduct of Sylvius have all been clearly demonstrated. No serious accidents have been encountered in the combined procedure of air injection.

Eight cases of successful approach to an intrapontine haematoma have so far been reported in the literature (Gros, Giraud and Latour, 1948; Scoville and Poppen, 1949; Myers, Scott, and Silverstein, 1961; Kempe, 1964; Matson, 1968; Dandy, 1969; Koos, Sunder-Plassman, and Salah, 1969; Obrador, Dierssen, and Odoriz, 1970). There have been, however, no follow-up studies by pneumoencephalography in a long survival case of primary pontine haemorrhage. Pneumoencephalo-roulette tomography was car- 
ried out 33 days after the onset in case 1, revealing a haematoma in the dorsal portion of the pons. Both postoperative tomography performed 183 days after onset and the third follow-up study done 545 days after the stroke demonstrated the atrophy of the brain-stem and the cerebellum. In case 2 the second pneumoencephalo-roulette tomography carried out 137 days after the first study revealed the pons to be markedly hollowed in the upper portion of its dorsal margin. The expansive mass lesion shown by the first tomogram had disappeared.

It has been described that the majority of small intracerebral haemorrhages would be replaced with glia or connective tissues within six months after bleeding, forming scars with haemosiderin pigment or small round cell infiltration (Meessen and Stochdorph, 1957). Changes in shape of the brain-stem observed in case 2 may indicate natural repair of intrapontine haemorrhage in the third stage (Meessen and Stochdorph, 1957). It is of interest to note the atrophy of the pons or the cerebellum in case 1. It is possible to presume that circulatory disturbances in the posterior fossa at the time of the stroke played a part in secondary atrophy of the brain-stem.

\section{REFERENCES}

Dandy, W. (1969). The brain. In Practice of Surgery, Vol. 12, pp. 1-671. Edited by D. Lewis and W. Walters. Prior: Hagerstown, Maryland.

Gros, C., Giraud, G., and Latour, H. (1948). Hématome spontané de la calotte protubérantielle operé et guéri. Presse Médicale, 56, 890.

Iwabuchi, T., and Suzuki, J. (1968). Diagnosis of acoustic neurinoma by pneumoencephalo-roulette tomography. Journal of Neurosurgery, 29, 307-309.

Kempe, L. G. (1964). Surgical removal of an intramedullary haematoma simulating Wallenberg's syndrome. Journal of Neurology, Neurosurgery, and Psychiatry, 27, 78-80.

Koos, W. T., Sunder-Plassmann, M., and Salah, S. (1969). Successful removal of a large intrapontine hematoma. Case report. Journal of Neurosurgery, 31, 690-694.

Matson, D. D. (1968). Surgery of posterior fossa tumors in childhood. In Clinical Neurosurgery, Vol. 15, pp. 247-264. Edited by J. Shillito, Jr. Williams and Wilkins: Baltimore. Matsukawa, A., Iwai, A., and Fukatsu, H. (1962). Studies on the roulette tomography. 1 . Roulette tomography. $\overrightarrow{0}$ Nippon Acta Radiologica, 21, 947-953. (In Japanese.)

Meessen, H., and Stochdorph, O. (1957). Erweichung und $\vec{\omega}$ Blutung. In Handbuch der speziellen pathologischen Anatomie und Histologie, XIII/IB, pp. 1384-1419. Edited by F. Henke and O. Lubarsch. Springer: Berlin.

Myers, J., Scott, M., and Silverstein, A. (1961). Cystic? hemangioblastoma of pons. Journal of Neurosurgery, 18, $\mathrm{G}$ 694-697.

Obrador, S., Dierssen, G., and Odoriz, B. J. (1970). Surgical Nu evacuation of a pontine-medullary hematoma. Case $\vec{\omega}$ report. Journal of Neurosurgery, 33, 82-84.

Scoville, W. B., and Poppen, J. L. (1949). Intrapeduncular hemorrhage of the brain. Successful operative approaci, with evacuation of clot and a seven and one-fourth yegr $\frac{7}{0}$ observation period. Archives of Neurology and Psychiafy (Chicago), 61, 688-694. 